\title{
Total dosage of gardenia fruit used by patients with mesenteric phlebosclerosis
}

\author{
Yutaka Nagata ${ }^{1,2^{*}}$, Tetsuo Watanabe ${ }^{3}$, Kazuhiko Nagasaka $^{1,2}$, Masaaki Yamada ${ }^{4}$, Masafumi Murai ${ }^{5,6}$, Sunao Takeuchi ${ }^{7}$, \\ Mai Murase ${ }^{7}$, Toshinori Yazaki ${ }^{7}$, Takayuki Murase ${ }^{7}$, Kenichi Komatsu ${ }^{8}$, Machiko Kaizuka ${ }^{8}$, Mika Sano ${ }^{9}$, Koji Asano $^{10}$, \\ Chikao Ando ${ }^{2}$ and Norihide Taniuchi ${ }^{7}$
}

\begin{abstract}
Background: Mesenteric phlebosclerosis (MP) is a disease characterized by fibrotic change or calcification of the mesenteric vein. Recently, there has been an increase in case reports of MP related to herbal medicine usage. Long-term intake of gardenia fruit (GF) is suspected as a possible cause. However, many GF users do not develop this disease and the association between GF and MP remains unclear. In this study, we investigated for the first time the dosage of GF used by patients with and without MP.

Methods: We used a medical chart review study design to assess the association between GF and MP. We reviewed patients with a history of intake of herbal medicines containing GF. Among these patients, we selected patients who were examined by colonoscopy and abdominal plain computed tomography (CT). We investigated the findings of colonoscopy, CT scan and histological examination. We assessed the total dosages of GF alongside the duration of ambulatory visit, the administration period of herbal medicine containing GF and pre-existing disease in order to compare MP cases and non-MP patients.

Results: Ten MP cases and 42 non-MP patients were analyzed. We summarized clinical findings of MP cases. All MP cases used more GF than non-MP patients and were administered more than approximately 5,000 grams of GF in cumulative dosage.

Conclusions: This study indicated that excessive intake of GF contributes to and/or accelerates the development of MP suggesting that long-term usage of GF in excessive amounts increases the risk of MP.
\end{abstract}

Keywords: Gardenia fruit, Herbal medicine, Kampo, Mesenteric phlebosclerosis, Sanshishi

\section{Background}

Mesenteric phlebosclerosis (MP) is a relatively new disease entity [1] and is also known as phlebosclerotic colitis [2-15]. Recently, it has been termed 'idiopathic' mesenteric phlebosclerosis [16-22], because its etiology remains unclear. In typical MP cases, abdominal X-rays and computed tomography (CT) scans demonstrate spotted or linear calcification around the right hemicolon $[2,8]$. The bronze coloration of colonic membrane is characteristic findings of this disease. In advanced MP cases, edema, ulceration, rigidity and stenosis on

\footnotetext{
* Correspondence: ynagata@suwachuo.jp

${ }^{1}$ Department of Oriental Traditional Medical Center, Suwa Central Hospital,

4300 Tamagawa, Chino, Nagano 391-8503, Japan

${ }^{2}$ River Side Clinic, Chino, Nagano, Japan

Full list of author information is available at the end of the article
}

endoscopic examination are also observed [1]. Several cases have been reported as chronic ischemic colitis $[23,24]$ and chronic ischemic lesions [25-28].

Previously published cases indicated an association with several conditions such as portal hypertension as a result of liver dysfunction [3, 4, 13], blood coagulation disorders [24], CREST syndrome [29], dialysis [15], vasculitis [6], diabetes mellitus [30, 31], hyperlipidemia [30] and hypertension [31] related to MP. Recently, the number of case reports of MP with a history of intake of herbal medicine has increased [9, 16-18, 32-34]. In particular, gardenia fruit (GF), 'Sanshishi' in Japanese, is attracting attention as a possible cause [33, 34]. Almost all of the reported herbal medicine-related MP cases took GF over a long period of time [33, 34]. As such, 
some are of the opinion that it is desirable to avoid long-term usage of medicines containing GF $[9,33]$.

It is also the case, however, that there were several patients that had taken GF for a longer period of time than MP cases in our experience [34]. There has not been sufficient data to assess this discrepancy. In this study, we first reviewed the dosages of GF in patients with or without MP.

The aim of this study was to review the dosage of GF used by patients with and without MP, and to resolve above-mentioned discrepant issue.

\section{Methods}

\section{Patients}

We reviewed ambulatory patients with a history of Kampo treatment from December 1, 2013 to May 25, 2015. Among the patients that reported usage of herbal medicines containing GF, we selected patients who were examined by colonoscopy and abdominal plain CT. We reviewed the findings of these clinical examinations performed from June 4, 2010 to May 25, 2015. A series of examinations were performed at the following facilities: Suwa Central Hospital, River Side Clinic and Shinsapporo Keiaikai Hospital.

\section{Herbal medicines containing gardenia fruit}

We used two dosage forms of Kampo preparations, namely extract preparations and traditional decocted herbal medicines. Medical-grade extract preparations of Kampo formulas containing GF as one of the ingredients used in Japan are listed in Table 1.

\section{Colonoscopy and CT scan}

Upon receipt of patient consent, colonoscopy and CT scan were performed to screen for MP and other diseases. We considered the diagnosis of MP from the findings of these clinical examinations and histological inspection [34]. Thickening of the affected colonic wall with calcification and associated calcification of the mesenteric vein and its tributaries on CT scan confirmed the presence of MP [2, 7]. We regarded the following findings as valuable changes at the early stage: slight calcification of the right hemicolon, increase in CT values in surrounding adipose tissue [4] and mild dilatation of the ileocecal vein.

\section{Histological inspection}

A diagnosis of MP was confirmed with histological inspection. Fibrotic deposition observed in the pericapillary region of the lamina propria [1] was the diagnostic criteria used in our hospital in this study. The specimens for examination were collected by colonoscopic biopsy. We used an excision sample of a colectomy in a patient undergoing an emergency operation. The biopsy was
Table 1 Medical-grade extract preparations of Kampo formulas containing gardenia fruit

\begin{tabular}{|c|c|c|}
\hline Kampo formula & GF (g/day) & Corporations manufacturing and marketing \\
\hline Bofutsushosan & $1.2 \mathrm{~g}$ & $\begin{array}{l}\text { Hon, JPS, Kot, Kra, Mat, Osu, } \\
\text { San, Tai, Toy, Tsu }\end{array}$ \\
\hline Gorinsan & $2.0 \mathrm{~g}$ & Toy, Tsu \\
\hline \multirow[t]{2}{*}{ Inchinkoto } & $3.0 \mathrm{~g}$ & Kot, Kra, Osu, Toy, Tsu \\
\hline & $2.0 \mathrm{~g}$ & Tei \\
\hline Kamikihito & $2.0 \mathrm{~g}$ & Kra, Osu, Tai, Toy, Tsu. \\
\hline Kamisyoyosan & $2.0 \mathrm{~g}$ & $\begin{array}{l}\text { Hon, Jun, JPS, Kot, Kra, Mat, Osu, } \\
\text { San, Tai, Tei, Toy, Tsu }\end{array}$ \\
\hline Keigairengyoto & $1.5 \mathrm{~g}$ & Osu, Tai, Tei, Tsu \\
\hline Orengedokuto & $2.0 \mathrm{~g}$ & $\begin{array}{l}\text { Hon, Jun, JPS, Kot, Kra, Osu, Sak, } \\
\text { San, Tai, Tei, Toa, Toy, Tsu }\end{array}$ \\
\hline \multirow[t]{2}{*}{ Ryutansyakanto } & $1.5 \mathrm{~g}$ & Kot, Tai \\
\hline & $1.0 \mathrm{~g}$ & San, Tsu \\
\hline Saikoseikanto & $1.5 \mathrm{~g}$ & Kot, Tei, Tsu \\
\hline Seihaito & $2.0 \mathrm{~g}$ & Tsu \\
\hline Seijobofuto & $2.5 \mathrm{~g}$ & Tsu, Osu \\
\hline \multirow[t]{2}{*}{ Shin'iseihaito } & $3.0 \mathrm{~g}$ & Kot, Tsu, Osu \\
\hline & $1.5 \mathrm{~g}$ & Kra \\
\hline Shishihakuhito & $3.0 \mathrm{~g}$ & Kot \\
\hline \multirow[t]{2}{*}{ Unseiin } & $1.5 \mathrm{~g}$ & Kra, Osu, Tei \\
\hline & $2.0 \mathrm{~g}$ & Toy, Tsu, Hon, Jun, Kot \\
\hline
\end{tabular}

GF gardenia fruit, Hon Honzo, Jun Junko, Kot Kotaro, Kra Kracie, Mat Matsuura, Osu Osugi, Sak Sakamoto, San Sanwa, Tai Taikodo, Tei Teikoku, Toa Toayakuhin, Toy Toyoyakko, Tsu Tsumura

performed in a case in which the color change of the colonic membrane was suspected. The biopsy specimens were collected from a location with a mild blue coloration or a characteristic bronze color change. We evaluated the degree of fibrillization and associated reduction of ductal cell density in the lamina propria (Additional file 1: Table S1) [34].

\section{Medication history and total dosages of gardenia fruit}

We reviewed the medication history of various kinds of herbal medicine containing GF. Moreover, we investigated the administration period of these medicines and the duration of ambulatory visit from clinical records. We excluded patients from this study who obtained GF-containing drugs from other facility. All patients started taking of GF at our facilities.

This allowed for investigation of duration from the beginning to the end of use for herbal medicines containing GF. We reviewed clinical records that recorded from January 23, 1997 to May 25, 2015.

We also calculated cumulative GF dosage, which is presented in Table 1. Various dosages of GF are consumed depending on the manufacturing of each drug. Mixtures of GF and other crude drugs are extracted with 
water for manufacturing a freeze-dried extract preparation. Concretely, only with the Bofutsushosan extract does, the dosage of GF vary from $0.4 \mathrm{~g}$ in a single administration ( $2.5 \mathrm{~g} /$ one packet) to $1.2 \mathrm{~g}$ in a daily dose (7.5 g/3 packets). In addition, we used traditional medicines, decocted with a mixture of crude drugs and water. The quantities of one-time dosages of GF in decocted traditional medicines were 1-3 g. We calculated the cumulative dosage of GF administered to each patient from such data.

\section{Pre-existing diseases}

We also investigated pre-existing diseases. The diagnostic criteria for pre-existing diseases were as follows: [elevated triglyceride (TG)]: $\mathrm{TG} \geq 150 \mathrm{mg} / \mathrm{dL}$ or taking therapeutic drug for a hypertriglyceridemia, [elevated low-density lipoprotein cholesterol (LDL-c)]: LDL-c $\geq$ $140 \mathrm{mg} / \mathrm{dL}$ or taking a therapeutic drug for hypercholesterolemia, [hypertension (HT)]: systolic blood pressure $\geq$ $130 \mathrm{mmHg}$ and/or diastolic blood pressure $\geq 85 \mathrm{mmHg}$ or taking an antihypertensive drug, and [diabetes mellitus (DM)]: fasting plasma glucose $\geq 110 \mathrm{mg} / \mathrm{dL}$ or HbA1c $(\mathrm{NGSP}) \geq 6.5 \%$ [35] or taking an oral hypoglycemic agent. These criteria were in agreement with criteria proposed by the Examination Committee for Metabolic Syndrome in Japan [36].

\section{Comparison between MP cases and non-MP patients}

We assessed the duration of ambulatory visit, the administration period of herbal medicine containing GF, cumulative GF dosage and pre-existing disease in order to compare MP cases and non-MP patients.

\section{Statistical analysis}

Statistical analysis was performed with JMP 9 (SAS Institute Japan, Tokyo). Data were expressed as mean \pm S.D.. Either a Student $t$ test, Fisher's exact test or Mann-Whitney $U$ test were used for statistical analysis of patient characteristics. A value of $P<0.05$ was considered statistically significant.

\section{Results}

\section{Reviewed patients}

We reviewed 1,927 patients with a history of Kampo treatment from December 1, 2013 to May 25, 2015. Two-hundred and forty-nine patients took herbal medicines containing GF.

\section{MP cases of enrolled patients}

This study enrolled 52 patients that had used GFcontaining herbal medicines and received colonoscopy and/or CT scan. We found $10 \mathrm{MP}$ cases in total at three institutions (Table 2); 5 were male, and 5 were female. The mean age at the time of diagnosis of MP cases was
66.1 years (range: 49 to 76 years old). All MP cases were diagnosed by histological inspection with colonic biopsy specimen or excision sample from an operation. One case (No. 3) developed into acute abdomen and was given a diagnosis of MP during emergency surgery. Two cases (No. 1, 10) were accidently found in CT. The other two cases were accidentally (No. 6, 8) pointed out in colonoscopy. The other five cases were diagnosed by a screening examination for MP as we actively searched for undiagnosed cases of MP actively with colonoscopy and CT scan.

We scrutinized the endoscopic findings of $9 \mathrm{MP}$ cases receiving colonoscopy. Typical bronze coloration was observed in 5 of 9 MP cases. Four cases remained a mild or dark blue coloration on colonoscopy.

Concerning the findings of CT scan, thickening of the affected colonic wall with calcification was observed in 5 of 9 MP cases who had a CT scan. Linear calcification of the mesenteric vein and its tributaries on CT scan was observed in 7 of 9 cases. Typical CT images were observed with a MP case (No. 2 of Table 2) (Fig. 1). Two cases continued to have slight calcification. Mild vasodilation of the ileocecal vein was observed in 1 of 9 cases.

The maximum dose of the MP cases was 15,792 $\mathrm{g}$ (No. 1 of Table 2). Colonoscopy showed typical bronze mucosa extending from the cecum to the transverse colon. Moreover, redness and erosion of the colonic membrane were observed in the cecum and the ascending colon (Fig. 2a, b). There was no color change in the descending colon (Fig. 2c). Severe wall thickening and typical linear calcification were observed on CT scan (Fig. 2d). The histological findings of moderate fibrotic lesions in pericapillary region of the lamina propria were observed (Fig. 3). Fibrillization was associated with a reduction of ductal cell density in part of the specimen.

\section{Pre-existing disease}

All MP cases had pre-existing disease (Table 2). Six MP cases had hypertension, and LDL-c was elevated in seven MP cases. There was no significant difference in each factor between MP cases and non-MP patients in this study (Table 3). Of 10 cases with MP, only one female case had liver disease. Although her dosage of GF was minimal in MP cases, typical linear calcification and wall thickening was observed.

\section{GF administration period}

The average administration period was 11.1 years (range: 4.0 to 15.9 years) in MP cases (Table 3). We also investigated the relation of the administration period of GF for MP cases and non-MP patients. Regarding this point, GF was administered in several non-MP patients longer than the shortest administration period of MP cases (Fig. 4). However, there were significant differences in 
Table 2 Characteristics and clinical findings of $10 \mathrm{MP}$ cases

\begin{tabular}{|c|c|c|c|c|}
\hline No. Age Sex & $\begin{array}{l}\text { Chief complaint/ } \\
\text { MP symptom }\end{array}$ & $\begin{array}{l}\text { Kampo formulas containing } \\
\text { GF/Clinical findings }\end{array}$ & $\begin{array}{l}\text { GF intake cumulative dosage } \\
\text { Administration period }\end{array}$ & $\begin{array}{l}\text { Pre-existing } \\
\text { disease }\end{array}$ \\
\hline \multirow[t]{2}{*}{$1.76 \mathrm{M}$} & Chief complaint Hypertension & Orengedokuto & $\begin{array}{l}15,792 \mathrm{~g} \\
14.1 \text { years }\end{array}$ & $\mathrm{DM}, \mathrm{HT}, \mathrm{LDL}-\mathrm{C}$ \\
\hline & MP symptom none & \multicolumn{2}{|c|}{$\begin{array}{l}\text { Clinical findings (location) } \\
\text { Colonoscopy: Bronze coloration (C to T) Redness and Erosion (C to A) } \\
\text { Histology: Moderate fibrillization } \\
\text { CT scan: Linear calcification (C to T) Wall thickening (C to A) }\end{array}$} & \\
\hline \multirow[t]{2}{*}{ 2. $76 \mathrm{M}$} & Chief complaint Hypertension & $\begin{array}{l}\text { Orengedokuto, } \\
\text { Orengedokuto, } \\
\text { Ryutansyakanto }\end{array}$ & $\begin{array}{l}14,683 \mathrm{~g} \\
15.9 \text { years }\end{array}$ & $H T, L D L-C$ \\
\hline & MP symptom none & \multicolumn{2}{|c|}{$\begin{array}{l}\text { Clinical findings (location) } \\
\text { Colonoscopy: Bronze coloration (C to T) } \\
\text { Histology: Severe fibrillization } \\
\text { CT scan: Linear calcification (C to T) Wall thickening (C to A) }\end{array}$} & \\
\hline \multirow[t]{2}{*}{ 3. $70 \mathrm{M}$} & Chief complaint Hypertension & $\begin{array}{l}\text { Orengedokuto, Kamisyoyosan, } \\
\text { Ryutansyakanto, Seihaito }\end{array}$ & $\begin{array}{l}8,119 \mathrm{~g} \\
11.9 \text { years }\end{array}$ & $\mathrm{DM}, \mathrm{HT}, \mathrm{TG}$ \\
\hline & $\begin{array}{l}\text { MP symptom lleus } \\
\text { (Colectomy) }\end{array}$ & \multicolumn{2}{|c|}{$\begin{array}{l}\text { Clinical findings (location) } \\
\text { Histology: Fibrillization of the colonic mucosa and the mesenteric } \\
\text { vein in excision sample } \\
\text { CT scan: Linear calcification (C to T) Wall thickening (C to A) }\end{array}$} & \\
\hline \multirow[t]{2}{*}{ 4. $49 \mathrm{~F}$} & $\begin{array}{l}\text { Chief complaint } \\
\text { Skin itching }\end{array}$ & $\begin{array}{l}\text { Unseiin, Kamisyoyosan, } \\
\text { Keigairengyoto, Orengedokuto }\end{array}$ & $\begin{array}{l}7,972 \mathrm{~g} \\
12.2 \text { years }\end{array}$ & LDL-C \\
\hline & MP symptom none & \multicolumn{2}{|c|}{$\begin{array}{l}\text { Clinical findings (location) } \\
\text { Colonoscopy: Mild blue coloration (C to A) } \\
\text { Decreased transparency of blood vessels (C to A) } \\
\text { Histology: Mild fibrillization } \\
\text { CT scan: Slight calcification, CT value increase, Mild }\end{array}$} & cal vein) \\
\hline \multirow[t]{2}{*}{ 5. $75 \mathrm{M}$} & $\begin{array}{l}\text { Chief complaint } \\
\text { Cutaneous pruritus }\end{array}$ & Unseiin & $\begin{array}{l}6,579 \mathrm{~g} \\
6.8 \text { years }\end{array}$ & $\mathrm{HT}$ \\
\hline & $\begin{array}{l}\text { MP symptom Constipation } \\
\text { Abdominal pain }\end{array}$ & \multicolumn{2}{|c|}{$\begin{array}{l}\text { Clinical findings (location) } \\
\text { Colonoscopy: Dark blue coloration (C to T) Redness and Erosion (C to A) } \\
\text { Histology: Severe fibrillization } \\
\text { CT scan: Linear calcification (C to T) Wall thickening (C to T) }\end{array}$} & \\
\hline \multirow[t]{2}{*}{$6.58 \mathrm{~F}$} & $\begin{array}{l}\text { Chief complaint Dermatitis } \\
\text { and Obesity }\end{array}$ & $\begin{array}{l}\text { Bofutsusyosan, Unseiin, } \\
\text { Keigairengyoto, Orengedokuto }\end{array}$ & $\begin{array}{l}6,499 \mathrm{~g} \\
13.5 \text { years }\end{array}$ & LDL-C \\
\hline & MP symptom none & \multicolumn{2}{|c|}{$\begin{array}{l}\text { Clinical findings (location) } \\
\text { Colonoscopy: Edematous membrane and Bronze coloration (C to A) } \\
\text { Histology: Concentric fibrillization surrounding capillary vessel }\end{array}$} & \\
\hline \multirow[t]{2}{*}{ 7. $68 \mathrm{M}$} & $\begin{array}{l}\text { Chief complaint } \\
\text { Cutaneous pruritus }\end{array}$ & Unseiin & $\begin{array}{l}6,372 \mathrm{~g} \\
12.2 \text { years }\end{array}$ & $\mathrm{DM}, \mathrm{HT}, \mathrm{LDL}-\mathrm{C}, \mathrm{TG}$ \\
\hline & MP symptom none & \multicolumn{2}{|c|}{$\begin{array}{l}\text { Clinical findings (location) } \\
\text { Colonoscopy: Bronze coloration (C to T) } \\
\text { Histology: Severe fibrillization } \\
\text { CT scan: Linear calcification (the ileocolic vein) }\end{array}$} & \\
\hline \multirow[t]{2}{*}{ 8. $58 \mathrm{~F}$} & $\begin{array}{l}\text { Chief complaint } \\
\text { Hot flush }\end{array}$ & $\begin{array}{l}\text { Kamisyoyosan, Kamikihito, } \\
\text { Orengedokuto, Shin'iseihaito }\end{array}$ & $\begin{array}{l}5,588 \mathrm{~g} \\
4.0 \text { years }\end{array}$ & LDL-C, TG \\
\hline & MP symptom none & \multicolumn{2}{|c|}{$\begin{array}{l}\text { Clinical findings (location) } \\
\text { Colonoscopy: Bronze coloration (C to T) } \\
\text { Histology: Mild - Moderate fibrillization } \\
\text { CT scan: Slight calcification and CT value increase (C to A) }\end{array}$} & \\
\hline \multirow[t]{2}{*}{ 9. $64 \mathrm{~F}$} & $\begin{array}{l}\text { Chief complaint } \\
\text { Flushed face, } \\
\text { Feeling of cold }\end{array}$ & Kamisyoyosan & $\begin{array}{l}5,408 \mathrm{~g} \\
11.4 \text { years }\end{array}$ & $H T, L D L-C, T G$ \\
\hline & MP symptom none & \multicolumn{2}{|c|}{$\begin{array}{l}\text { Clinical findings (location) } \\
\text { Colonoscopy: Mild blue coloration (C to T) } \\
\text { Histology: Mild - Moderate fibrillization } \\
\text { CT scan: Linear calcification (C to A) }\end{array}$} & \\
\hline
\end{tabular}


Table 2 Characteristics and clinical findings of 10 MP cases (Continued)

\begin{tabular}{|c|c|c|c|c|}
\hline \multirow[t]{2}{*}{ 10. $67 \mathrm{~F}$} & $\begin{array}{l}\text { Chief complaint } \\
\text { Hepatitis }\end{array}$ & Orengedokuto & $\begin{array}{l}5,379 \mathrm{~g} \\
9.4 \text { years }\end{array}$ & Liver disease \\
\hline & MP symptom none & \multicolumn{3}{|c|}{$\begin{array}{l}\text { Clinical findings (location) } \\
\text { Colonoscopy: Mild blue coloration (C to T) } \\
\text { Histology: Mild - Moderate fibrillization } \\
\text { CT scan: Linear calcification (C to T) Wall thickening (C to A) }\end{array}$} \\
\hline
\end{tabular}

CT computed tomography, GF gardenia fruit, MP mesenteric phlebosclerosis, DM diabetes mellitus, $H T$ hypertension, $L D L-c$ elevated low-density lipoprotein cholesterol, $T G$ elevated triglyceride, $C$ the caecum, $A$ the ascending colon, $T$ the transverse colon, Oblique type medicines, traditional decocted herbal medicines

the duration of ambulatory visit and GF administration period between MP cases and non-MP patients (Table 3).

\section{Cumulative dosage of gardenia fruit}

We investigated the cumulative dosages of GF in all 52 patients, including the $10 \mathrm{MP}$ cases (Fig. 5). The ten cases with a definitive diagnosis of MP had all used more GF than non-MP patients. There was a remarkably significant difference between MP cases and non-MP patients in cumulative GF dose (Table 3).

The minimum dosage of GF was 5,379 $\mathrm{g}$ in MP cases. The maximum dose of GF administered to non-MP patients was 4,542 g. There was a constant distinction in GF dosage for MP diagnosed cases and non-diagnosed patients (Fig. 5).

\section{Relationship between GF administration period and GF dose}

We presented a relation between GF administration period and cumulative dosages of GF in each patient in all 52 subjects in Fig. 6. Although there were several non-MP patients that had taken GF for a longer period of time than MP cases, all non-MP patients used less GF than all MP cases.

\section{Discussion}

In this study, we reviewed $10 \mathrm{MP}$ cases and 42 non-MP patients. All MP cases had used more GF than non-MP patients. Our results suggested that excessive intake of GF contributes to and/or accelerates the development of MP.
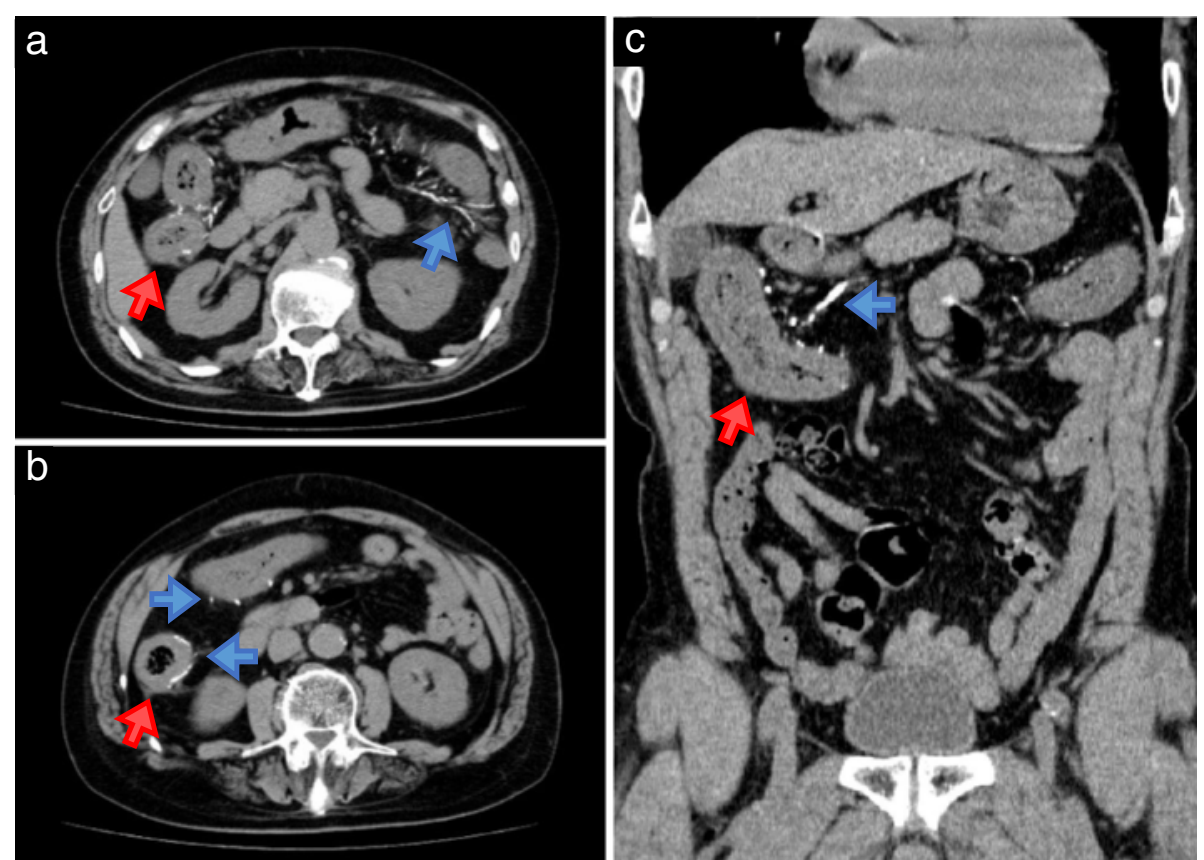

Fig. 1 Typical findings of CT scan in MP cases (No. 2 in Table 2). Typical calcification and wall thickening in the transverse colon (a) and the ascending colon (b). Linear calcification in the transverse colon in coronal section (c). The blue colored arrows indicate the typical calcification. The red colored arrows indicate the thickening in the colon. CT, computed tomography; MP, mesenteric phlebosclerosis 


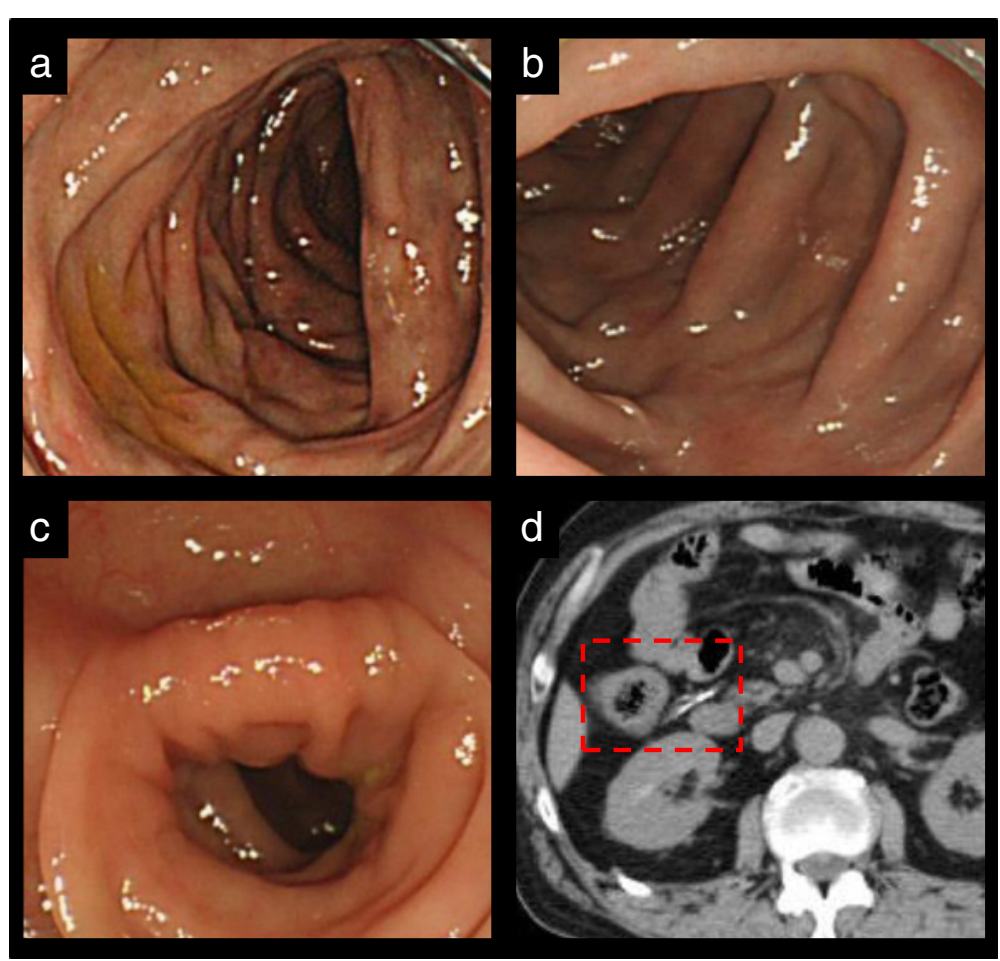

Fig. 2 Clinical findings of colonoscopy and CT scan in MP cases (No. 1 in Table 2). Bronze coloration and redness in the ascending colon (a), bronze coloration in the hepatic flexure (b) and normal membrane in the descending colon (c) on colonoscopy. Linear calcification and wall thickening in the ascending colon (d) on CT scan. CT, computed tomography; MP, mesenteric phlebosclerosis
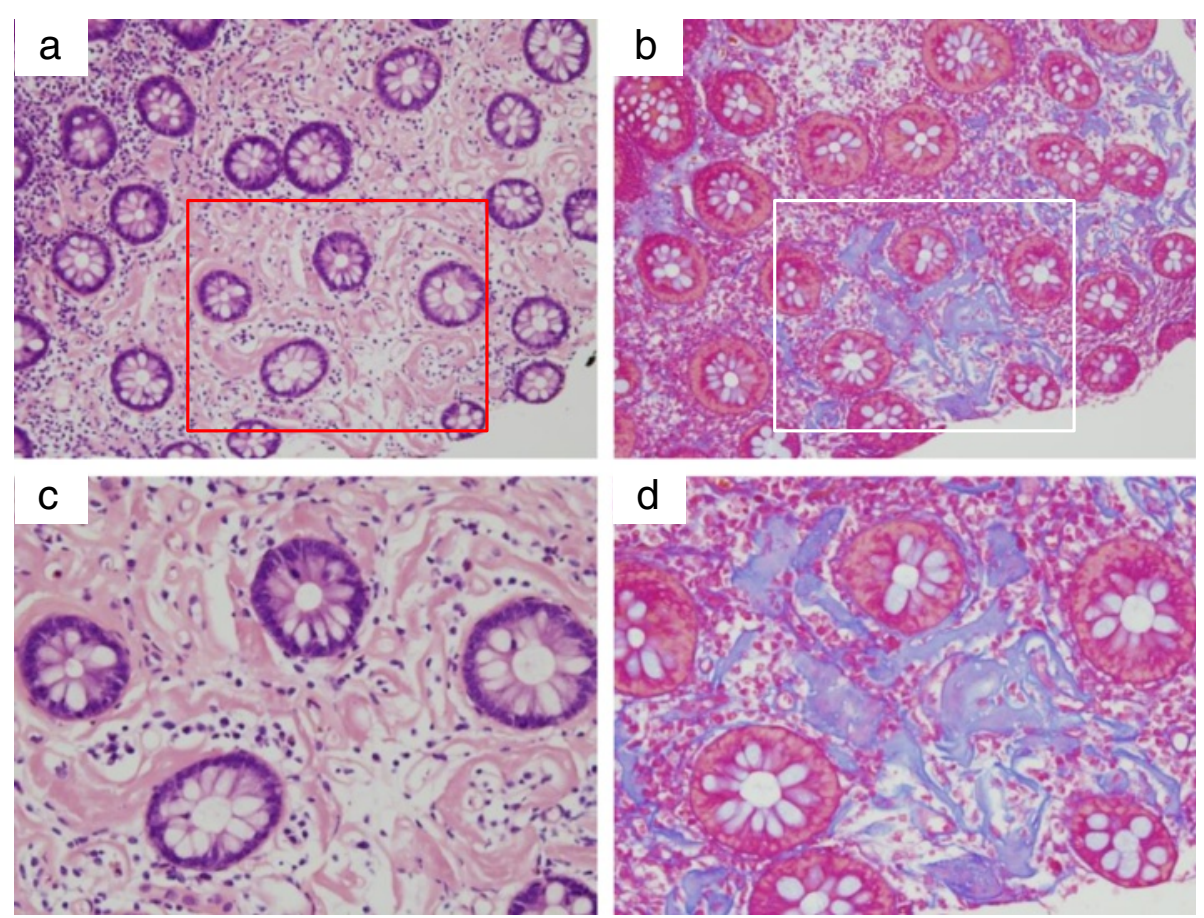

Fig. 3 Histological findings in MP Case (No.1 in Table 2). Moderate pericapillary concentric fibrillization was noted in the specimens collected at the ascending colon. The fibrillization was associated with a reduction of ductal cell density in part of specimen. [Haematoxylin and Eosin stain: a $\times 10$ : c $\times 20]$. [Azan stain: $\mathbf{b} \times 10, \mathbf{d} \times 20]$. MP, mesenteric phlebosclerosis 
Table 3 Comparison of non-MP patients with MP cases

\begin{tabular}{llll}
\hline & $\begin{array}{l}\text { non-MP } \\
(n=42)\end{array}$ & MP $(n=10)$ & $P$ value \\
\hline Age (year) & $58.2 \pm 14.8$ & $66.1 \pm 9.1$ & $.1113^{\mathrm{a}}$ \\
& $58.5(16-86)$ & $67.5(49-77)$ & \\
Sex (male/female) & $11 / 31$ & $5 / 5$ & $.2509^{\mathrm{b}}$ \\
BMI (kg/m²) & $22.5 \pm 3.8$ & $23.0 \pm 2.3$ & $.7024^{\mathrm{a}}$ \\
& $22.5(16.0-31.4)$ & $22.8(19.5-27.7)$ & \\
DM (yes/no) & $5 / 37$ & $3 / 7$ & $.1710^{\mathrm{b}}$ \\
HT (yes/no) & $14 / 28$ & $6 / 4$ & $.1562^{\mathrm{b}}$ \\
LDL-c (yes/no) & $19 / 23$ & $7 / 3$ & $.2913^{\mathrm{b}}$ \\
TG (yes/no) & $8 / 34$ & $4 / 6$ & $.2125^{\mathrm{b}}$ \\
Liver disease (yes/no) & $0 / 42$ & $1 / 9$ & $.1923^{\mathrm{b}}$ \\
Herbal medicine treatment & & & $.0001^{\mathrm{c}}$ \\
Ambulatory visit (years) & $6.8 \pm 4.3$ & $13.9 \pm 3.0$ & \\
& $6.3(1.5-17.9)$ & $15.1(6.5-16.3)$ & \\
GF administration period & $4.2 \pm 3.7$ & $11.1 \pm 3.5$ & $.0001^{\mathrm{c}}$ \\
(years) & $3.1(0.2-14.8)$ & $12.1(1.5-15.9)$ & \\
Cumulative dosage & $1319.7 \pm 1077.7$ & $8239.1 \pm 3817.4$ & $<.0001^{\mathrm{c}}$ \\
of GF (g) & 997.5 & 6539.0 & \\
& $(54.0-4542.0)$ & $(5379.0-15792.0)$ & \\
\hline
\end{tabular}

Data are expressed as mean \pm S.D. and median (minimum - maximum) $M P$ mesenteric phlebosclerosis, $B M I$ body mass index, $D M$ diabetes mellitus, $H T$ hypertension, $L D L-c$ elevated low-density lipoprotein cholesterol, $T G$ elevated triglyceride, GF gardenia fruit

${ }^{a}$ Comparison between non-MP group and MP group by Student's $t$ test ${ }^{\mathrm{b}}$ Comparison between non-MP group and MP group by Fisher's exact test ${ }^{C}$ Comparison between non-MP group and MP group by Mann-Whitney U-test

The essential pathology of "phlebosclerosis" has been described as a fibrous degeneration of the intima and/or media and adventitia with or without calcification [37]. Some pathogenic and etiological factors such as inflammation, thrombosis, mechanical stress and calcium deposition are mentioned, however, the role of these factors have not been established.

Although the actual cause and pathogenesis of MP remains largely unclear, GF has attracted attention as a possible cause of MP $[9,33]$. Published reports provided three viewpoints regarding the suspected association between GF and MP: (1) most herbal medicine-related MP cases took GF for a long time, (2) most MP cases were reported from the Asia region where GF is commonly used, and (3) a favorite site of MP is the right hemicolon where the constituents of GF are largely metabolized. Our results appear to support and rationalize these suggestions.

Firstly, GF has been reported as a common ingredient used in MP cases with a history of herbal treatment [33]. Similarly, all MP cases at our facilities had used GF and there was no other common ingredient apart from GF in these cases. The long period, spanning several years or over a decade, suggested that such a large quantity of GF can explain the long-term intake of GF in MP cases.

In previous research, the average length of herbal treatment leading to development of MP was reported as 13.6 years in the largest-scale study [38]. In this study, the average length of GF administration period was 11.1 years in MP cases (Table 3). We paid particular attention to initial changes such as a thickened colon and elevated CT value on CT scans, and slight color change on colonoscopy. This might have allowed us to detect MP cases earlier than other facilities.

Secondly, an association between GF and MP can be explained by regional/cultural factors. It is characteristic that almost all reported cases of MP were in individuals from Asian countries such as Japan [1, 2, 4, 5, 7, 8, 16, 17], Taiwan including Taiwanese residents in Canada [10, 12, 14, 18, 20, 39], Hong Kong [11, 40], Korea [13, 19, 41] and China including a Chinese resident in the USA $[15,21,22$, 32]. GF has long been used in eastern Asia as a crude drug or coloring agent. GF is a one of the most useful herbal medicines applied in Kampo treatment. Herbal medicines containing GF are often necessary to improve a patient's quality of life. They are useful for the relief of various symptoms (Additional file 2: Table S2) and have been used in the treatment of several pathological conditions [42-50]. In fact, symptoms of our MP cases were ameliorated by administration of Kampo formulas containing GF. Therefore, patients wanted to receive these drugs. As such, Asian people have a high chance of taking more GF than residents of other regions.

Finally, a favorite site of MP is common to the section where the constituents of GF are largely decomposed by intestinal bacteria. Previous reports supposed that certain toxic biochemical agents or water-soluble irritants absorbed from the ascending colon cause chronic damage $[16,18]$. We also consider that sustained stimulation with a suitable dose of GF could form a MP lesion. The constituents of herbal medicine are orally administered and brought into contact with enteric bacterium. They are metabolized to be bioactive, ineffective, or toxic compounds before they are absorbed from the gastrointestinal tract [51]. It is reported that intestinal bacteria play an important role in the intestinal metabolism of GFcomponents [52, 53]. Because the distal ileum and colon have bacteria in large quantities, the main area affected by the metabolites passing through it might be at the right side colon [54].

The metabolism of the main constituents of GF has been previously studied [53, 55-57]. Metabolites from GF include eight major bioactive constituents, including geniposidic acid, chlorogenic acid, genipin-1- $\beta$-gentiobioside, geniposide, genipin, rutin, crocin- 1 and crocin- 2 [57]. Among these constituents, geniposide has been suggested as a possible cause of MP [33]. Geniposide-induced 


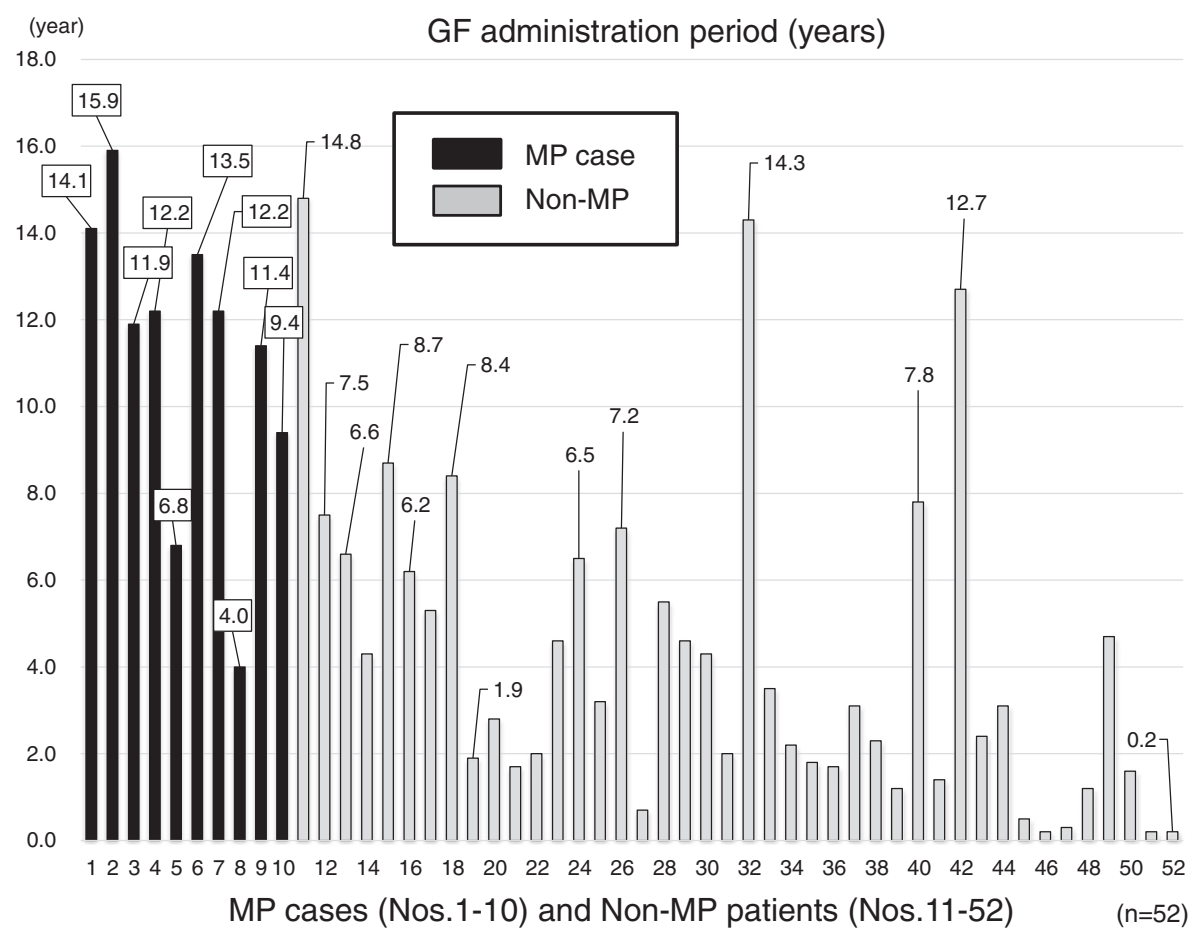

Fig. 4 GF administration period (years) in examined cases with or without MP $(n=52)$. There were several non-MP patients who exceeded MP cases for duration of administration period of GF. They did not develop MP in spite of their long-term GF administration. GF, gardenia fruit; MP, mesenteric phlebosclerosis

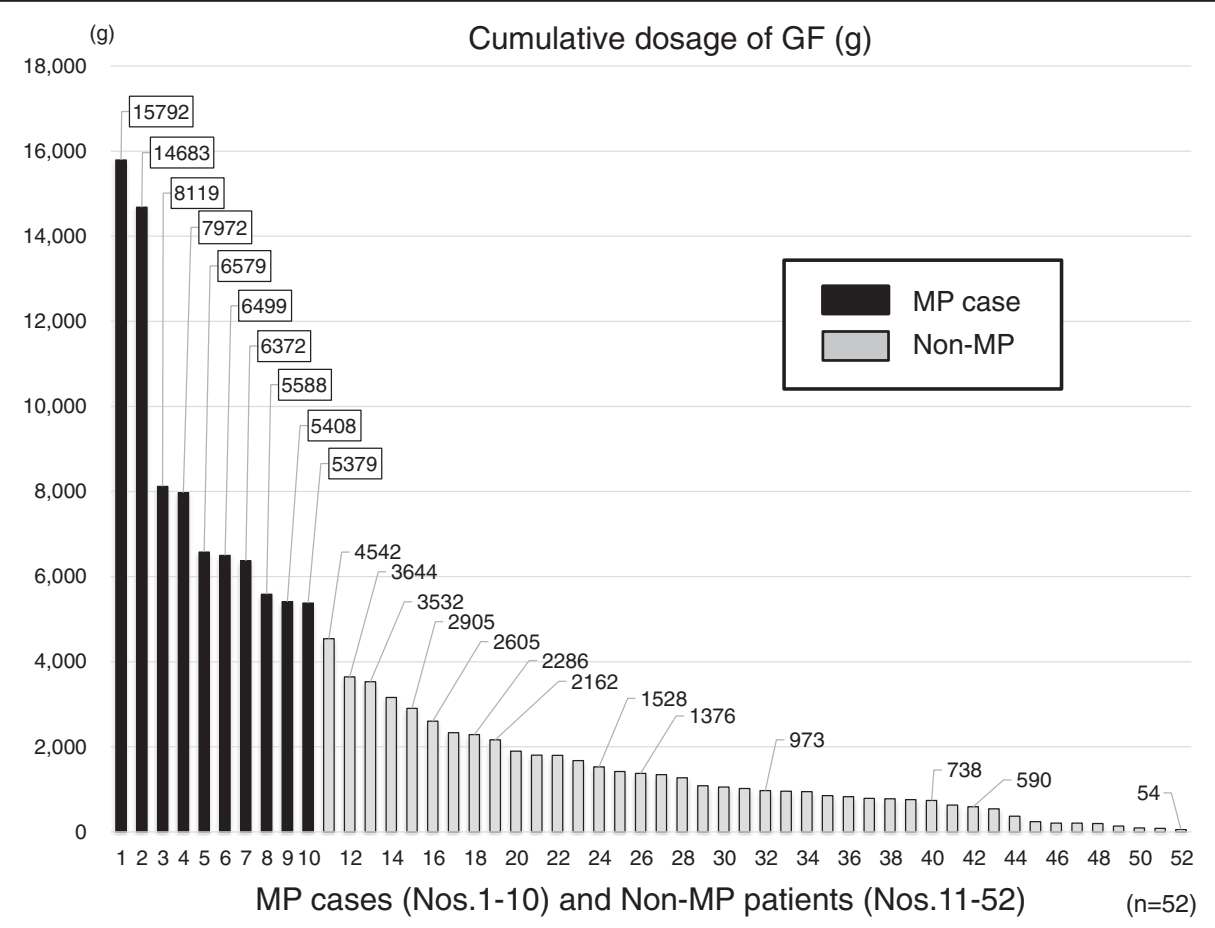

Fig. 5 Cumulative GF dosage (g) in examined cases with or without MP $(n=52)$. The total dosages of GF consumed by MP cases were larger than those in other 42 patients. The total amount of 5,379-15,792 g of GF was used in MP cases. The maximum dose of the non-MP patients was 4,542 g. GF, gardenia fruit; MP, mesenteric phlebosclerosis 


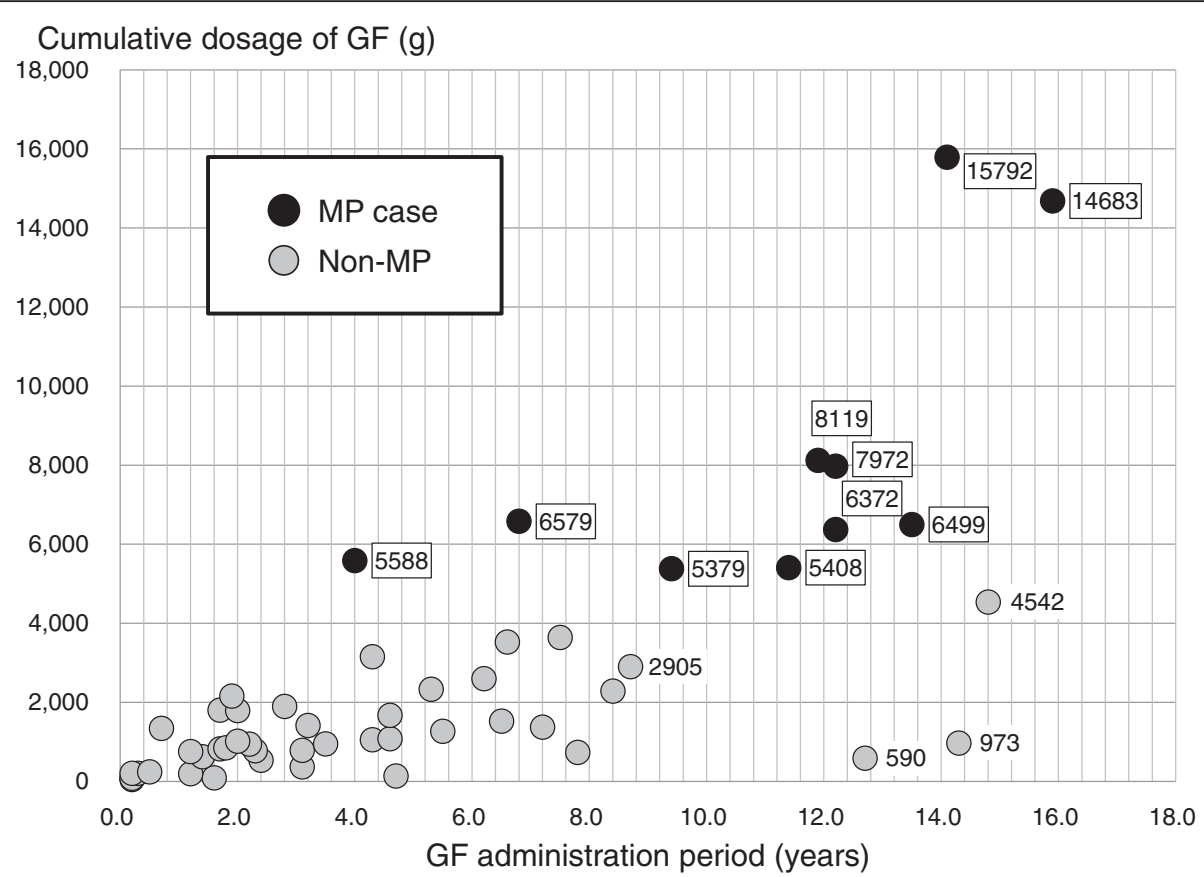

Fig. 6 Relation between GF administration period and cumulative dosages of GF ( $n=52)$. There were several patients that had taken GF for a longer period of time than MP cases. All MP cases used more GF than non-MP patients. GF, gardenia fruit; MP, mesenteric phlebosclerosis

hepatotoxicity has been reported previously $[58,59]$. The hepatotoxicity of high doses of geniposide has also been reported to be linked to oxidative stress [59]. Geniposide, a main iridoid glucoside component of GF, is converted to aglycone, genipin $[55,56]$. When cross-linked with amino acid, genipin can be observed as having a blue coloration [60]. This might relate to the blue-colored mucosa observed in MP. Collectively, the ingredients of GF seem to have some kind of influence, but it is still unknown how they specifically act on MP.

Until recently, it was not known that GF had the potential to be harmful. It is now important, however, to consider the possible development of MP. When MP progresses without clinical checkup, mesenteric circulatory failure may induce severe constipation, ileus, bowel dysfunction and ischemic colitis. Moreover, total or partial colectomy has often been performed for such severe cases $[3,4,6,26,28]$. As such, due to various concerns in the literature, calls for awareness and caution associated with GF and MP have been raised. We are also cautious, however, about the possibility that excessive concern keeps away a patient from effective treatment. Currently, without sufficient data, special attention should be given to any lengthy period of GF use that spans over years.

Looking more carefully at longer periods of use, we confirmed in this study that several non-MP patients had taken GF for a longer period of time than MP cases. These non-MP patients were administered GF intermittently and/or at a low daily dose of GF. Therefore, if the cumulative dose of GF is kept to low levels, MP occurrence or development is likely to be avoided.

MP is sometimes missed or misdiagnosed due to a lack of typical findings. However, we were able to detect early MP with histological inspection in a colonic biopsy specimen. If there are findings such as a mild blue coloration of the colonic membrane, a biopsy should be performed. However, it is difficult to diagnose MP in this way since most patients do not wish to undergo a colonoscopy. In such cases, the overall cumulative dose of GF might provide a criterion for determining whether or not the patient has MP. Even if these examinations are not performed, it is recommended that any patients with excessive intake of GF should refrain from further use.

The most notable result of this study is an association between GF intake and the emergence of MP. Our results suggest that an excessive intake of GF, approximately $5,000 \mathrm{~g}$ in this study, contributes to and/or accelerates the development of MP. The threshold may increase or decrease with the contribution of several other conditions. It is also necessary to consider etiologies of MP other than GF. We confirmed all MP cases had pre-existing disease, but there was no significant difference in each lifestyle disease between MP cases and non-MP patients in this pilot study. However, we had an impression that they were numerically different. The non-significant results in this study could be because of 
the small sample size, particularly in the MP group $(\mathrm{n}=$ 10). The correlation between pre-existing disease and onset of MP can be validated in additional investigation with larger patient population. Further verification of the relationship with other risk factors is needed. Although our study suggested an association between MP development and cumulative GF dose, we did not reach an identification of the causal ingredient in GF. Thus, identifying the actual toxic agent is our next task.

This study is the first report about the total GF cumulative dose with or without MP in patients confirmed to have taken GF. Specifically, the cumulative dosage of GF seems to be responsible for developing MP rather than the duration of its administration.

\section{Limitations}

We excluded patients who were already taking GF at another medical facility prior to coming to our facilities from the study. We also excluded patients who took over-the-counter herbal preparations containing GF. If this was not recorded in the medical charts, it could be possible that some patients had obtained GF containing medical-grade preparations from another medical facility or GF-containing over-the-counter preparations from a pharmacy. If such cases exist, then it is possible that the threshold for cumulative GF dosage may be higher.

\section{Conclusion}

In this study, all MP cases used more GF than non-MP patients. This result indicated that excessive intake of GF contributes to and/or accelerates the development of $\mathrm{MP}$, suggesting that long-term usage of GF in excessive amounts increases the risk of MP.

\section{Abbreviations \\ $C T$, computed tomography; DM, diabetes mellitus; GF, gardenia fruit; $H T$, hypertension; LDL-c, low-density lipoprotein cholesterol; MP, Mesenteric phlebosclerosis; TG, triglyceride}

\section{Acknowledgements \\ The authors thank Dr. Go Suzuki for providing clinical information. Dr. Nobuko Nakagawa got the consent from patients as attending physician in clinical practice. Dr. Aritaka Matsuyama and Minoru Saito conducted the colonoscopy. Dr. Yasuyuki Takamizawa and Makoto Araki supervised the research.}

\section{Funding source}

No fund was provided by any funding agency for this study.

\section{Availability of data and materials}

The data and materials supporting the conclusions of this article are presented in this main paper.

\section{Authors' contributions}

YN designed the research. YN and TW wrote the manuscript. YN and MY analyzed the data. YN, TW, KN, M.Murai, ST, M.Murase, TY, TM, KK, MK, CA and NT performed the research. MS evaluated radiological findings. KA evaluated pathological findings. KN, CA, and NT supervised. YN and TW contributed equally. All authors approved the submission of the final version.

\section{Competing interests}

The authors declare that they have no competing interest.

\section{Consent for publication}

All authors consent to this manuscript's publication.

\section{Ethics approval and consent to participate}

This study was approved by the Ethics Committee in Suwa Central Hospital. Meticulous attention was taken to avoid specifying individual patients. The study was done in accordance with the ethical standards of the Helsinki Declaration of 1964 (as revised in 2013). We used a medical chart review study design and we reviewed the findings of colonoscopy, CT scan and histological examination. These examinations were performed upon receipt of patient consent.

\section{Author details}

'Department of Oriental Traditional Medical Center, Suwa Central Hospital, 4300 Tamagawa, Chino, Nagano 391-8503, Japan. ${ }^{2}$ River Side Clinic, Chino, Nagano, Japan. ${ }^{3}$ Department of Japanese Oriental Medicine and Rheumatology, Toyama Prefectural Central Hospital, Toyama, Toyama, Japan. ${ }^{4}$ Department of Epidemiology and Health Policy, Graduate School of Medicine and Pharmaceutical Sciences, University of Toyama, Toyama, Toyama, Japan. ${ }^{5}$ Hokudaimae Clinic, Hokkaido Kampo Medical Center, Sapporo, Hokkaido, Japan. ${ }^{6}$ Shinsapporo Keiaikai Hospital, Sapporo, Hokkaido, Japan. ${ }^{7}$ Department of Internal medicine, Suwa Central Hospital, Chino, Nagano, Japan. ${ }^{8}$ Department of Surgery, Suwa Central Hospital, Chino, Nagano, Japan. 'Department of Radiology, Suwa Central Hospital, Chino, Nagano, Japan. ${ }^{10}$ Department of Pathology, Suwa Central Hospital, Chino, Nagano, Japan.

Received: 25 November 2015 Accepted: 29 June 2016

Published online: 11 July 2016

\section{References}

1. Iwashita A, Yao T, Schlemper RJ, et al. Mesenteric phleboscrelosis: a new disease entity causing ischemic colitis. Dis Colon Rectum. 2003;46:209-20.

2. Yao T, Iwashita A, Hoashi T, et al. Phlebosclerotic colitis: value of radiography in diagnosis-report of three cases. Radiology. 2000;214:188-92.

3. Kimura Y, Kashima K, Daa T, et al. Phlebosclerotic colitis coincident with carcinoma in adenoma. Pathol Int. 2003;53:721-5.

4. Kusanagi M, Matsui O, Kawashima H, et al. Phlebosclerotic colitis: imaging-pathologic correlation. Am J Roentgenol. 2005;185:441-7.

5. Saito Y, Taniguchi M, Tagawa K, et al. Phlebosclerotic colitis with deep circumferential ulceration: three-year endoscopic follow-up. Report of a case. Dis Colon Rectum. 2005:48:2347-51.

6. Mikami T, Hatate K, Kokuba Y, et al. A case of phlebosclerotic colitis: vasculitis as a possible origin. Kitasato Med J. 2005;35:75-9.

7. Takamoto F, Ishizaki H, Maehara T. Plebosclerotic colitis. Radiat Med. 2008;26:164-7.

8. Hozumi H, Hokari R, Shimizu M, et al. Phlebosclerotic colitis that was difficult to distinguish from collagenous colitis. Dig Endosc. 2014;26:594-8.

9. Hirasaki S, Matsumura K. Development of phlebosclerotic colitis under treatment with Chinese herbal therapy. Intern Med. 2014;53:1709-10.

10. Markos V, Kelly S, Yee WC, et al. A. Phlebosclerotic colitis: imaging findings of a rare entity. Am J Roentgenol. 2005;184:1584-6.

11. Ho TJ, Cheung CW, Wong WM, et al. Phlebosclerotic colitis: an unusual cause of ischemic colitis in a 65-year-old man. J HK Coll Radiol. 2005;8:53-8.

12. Jan YT, Yang FS. Phlebosclerotic colitis. J Am Coll Surg. 2008;207:785.

13. Kang HY, Noh R, Kim SM, et al. Phlebosclerotic colitis in a cirrhotic patient with portal hypertension: the first case in Korea. J Korean Med Sc. 2009;24:1195-9.

14. Chen MT, Yu SL, Yang TH. A case of phlebosclerotic colitis with involvement of the entire colon. Chang Gung Med J. 2010;33:581-5.

15. Song $J H$, Kim Jl, Jung JH, et al. A case of phlebosclerotic colitis in a hemodialysis patient. Korean J Gastroenterol. 2012;59:40-3.

16. Miyazaki M, Nakamura S, Matsumoto T. Idiopathic mesenteric phlebosclerosis occurring in a wife and her husband. Clin Gastroenterol Hepato. 2009;7:e32-3.

17. Nishiura $H$, Nakase $H$, Chiba T. Sustained abdominal discomfort in a 57-year-old woman. Idiopathic mesenteric phlebosclerosis. Gut. 2010;59:578,594 
18. Chang KM. New histologic findings in idiopathic mesenteric phlebosclerosis: clues to its pathogenesis and etiology-probably ingested toxic agent-related. J Chin Med Assoc. 2007;70:227-35.

19. Jung HG, Koh JW, Lee MY. A case of idiopathic mesenteric phlebosclerosis. Korean J Gastroenterol. 2008;52:261-4.

20. Lin PY, Chai CY, Chang CC. Recurrent abdominal pain in a 55-year-old woman. Diagnosis: Idiopathic mesenteric phlebosclerosis. Gastroenterology. 2011:141:36-404

21. Siao D, Thoeni R, Grenert JP, Day LW. A rare presentation of abdominal pain: idiopathic mesenteric phlebosclerosis. Am J Gastroenterol. 2012;107:1759-60.

22. Guo F, Zhou YF, Zhang F, et al. Idiopathic mesenteric phlebosclerosis associated with long-term use of medical liquor: two case reports and literature review. World J Gastroenterol. 2014;20:5561-6.

23. Koyama N, Koyama H, Hanajima T, et al. Chronic ischemic colitis causing stenosis, report of a case. I to cho (Stomach and Intestine). 1991;26:455-60.

24. Ikehata A, Hiwatashi N, Kawarada H, et al. Chronic ischemic colitis associated with marked calcification of the mesenteric vessels, report of two cases. Dig Endosc. 1994;6:355-64.

25. Arimura Y, Kondoh Y, Kurokawa S, et al. Chronic ischemic colonic lesion caused by phlebosclerosis with calcification. Am J Gastroenterol. 1998;93:2290-2.

26. Yoshinaga S, Harada N, Araki Y, et al. Chronic ischemic colonic lesion caused by phlebosclerosis: a case report. Gastrointest Endosc. 2001;53:107-11.

27. Oshitani N, Matsumura Y, Kono M, et al. Asymptomatic chronic intestinal ischemia caused by idiopathic phlebosclerosis of mesenteric vein. Dig Dis Sci. 2002;47:2711-4.

28. Nishimura G, Nagai N, Ninomiya I, et al. Chronic ischemic lesion of the colon caused by phlebosclerosis of ileocolic mesenteric vein. Dig Endosc. 2004;16:169-71.

29. Kitamura T, Kubo M, Nakanishi T, et al. Phlebosclerosis of the colon with positive anti-centromere antibody. Intern Med. 1999;38:416-21.

30. Iwashita A. Pathomorphology of ischemic intestinal lesion according to each cause. I to cho (Stomach and Intestine). 1993;28:927-41.

31. Hirata I. Radiologic diagnosis of idiopathic mesenteric phlebosclerosis. I to cho (Stomach and Intestine). 2009;44:170-81.

32. Wang HH, Wu YC, Liu CH, et al. Mesenteric phlebosclerosis: an unexpected cause of abdominal pain. J Gastrointestin Liver Dis. 2012;21:344.

33. Hiramatsu K, Sakata H, Horita Y, et al. Mesenteric phlebosclerosis associated with long-term oral intake of geniposide, an ingredient of herbal medicine. Aliment Pharmacol Ther. 2012;36:575-86.

34. Nagata Y, Watanabe T, Nagasaka K, et al. Clinical search for undiagnosed mesenteric phlebosclerosis at outpatient departments specializing in herbal (Kampo) medicine. Intern Med. 2016;55:573-81.

35. Committee of the Japan Diabetes Society on the Diagnostic Criteria of Diabetes Mellitus, Seino Y, Nanjo K, et al. Report of the committee on the classification and diagnostic criteria of diabetes mellitus. J Diabetes Investig. 2010;1:212-28.

36. The Examination Committee for Criteria of Metabolic Syndrome. Definition and criteria of metabolic syndrome. J Japanese Soc Intern Med. 2005;94:794-809.

37. Tzogias L, Labropoulos N, Amaral SI, et al. Distribution and clinical impact of phelebosclerosis. Int Angiol. 2011;30:212-20.

38. Shimizu S, Matsui T, Hibi T. Results of national survey on mesenteric phlebosclerosis. Nihon Shokakibyo Gakkai Zasshi. 2014;111(suppl-2):780.

39. Tsai CC, Chou JW, Chiang IP, et al. Mesenteric phlebosclerosis. Intern Med. 2008;47:183-4

40. Kwok KY, Lo SS, Fung HS, et al. Mesenteric phlebosclerosis - features on plain radiograph and computed tomography scan. J HK Coll Radiol. 2010;12:136-8.

41. Choi JM, Lee KN, Kim HS, et al. Idiopathic phlebosclerotic colitis: a rare entity of chronic ischemic colitis. Korean J Gastroenterol. 2014;63:183-6.

42. Okada K, Shoda J, Kano M, et al. Inchinkoto, a herbal medicine, and its ingredients dually exert Mrp2/MRP2-mediated choleresis and Nrf2-mediated antioxidative action in rat livers. Am J Physiol Gastrointest Liver Physiol. 2007:292:G1450-63.

43. Watari H, Shimada Y, Tohda C. New Treatment for Alzheimer's Disease, Kamikihito, Reverses Amyloid- $\beta$-Induced Progression of Tau Phosphorylation and Axonal Atrophy. Evid Based Complement Alternat Med. 2014:2014:706487.

44. Mantani N, Hisanaga A, Kogure T, et al. Four cases of panic disorder successfully treated with Kampo (Japanese herbal) medicines: Kami-shoyo-san and Hange-koboku-to. Psychiatry Clin Neurosci. 2002;56:617-20.
45. Chen LC, Tsao YT, Yen KY, et al. A pilot study comparing the clinical effects of Jia-Wey Shiau-Yau San, a traditional Chinese herbal prescription, and a continuous combined hormone replacement therapy in postmenopausal women with climacteric symptoms. Maturitas. 2003;44:55-62.

46. Higaki S, Morohashi M. Propionibacterium acnes lipase in seborrheic dermatitis and other skin diseases and Unsei-in. Drugs Exp Clin Res. 2003;29:157-9.

47. Arakawa K, Saruta T, Abe K, et al. Improvement of accessory symptoms of hypertension by TSUMURA Orengedokuto Extract, a four herbal drugs containing Kampo-Medicine Granules for ethical use: a double-blind, placebo-controlled study. Phytomedicine. 2006;13:1-10.

48. Okamoto $\mathrm{H}$, Chino A, Hirasaki $\mathrm{Y}$, et al. Orengedoku-to augmentation in cases showing partial response to yokukan-san treatment: a case report and literature review of the evidence for use of these Kampo herbal formulae. Neuropsychiatr Dis Treat. 2013;9:151-5.

49. Hidaka T, Yonezawa R, Saito S. Kami-shoyo-san, Kampo (Japanese traditional medicine), is effective for climacteric syndrome, especially in hormone-replacement-therapy-resistant patients who strongly complain of psychological symptoms. J Obstet Gynaecol Res. 2013;39:223-8.

50. Yamamoto M, Miura N, Ohtake N, et al. Genipin, a metabolite derived from the herbal medicine Inchin-ko-to, and suppression of Fas-induced lethal liver apoptosis in mice. Gastroenterology. 2000;118:380-9.

51. Scheline RR. Metabolism of foreign compounds by gastrointestinal microorganisms. Parmacol Rev. 1973;25:451-523.

52. Kawata Y, Hattori M, Akao T, Kobayashi K, Namba T. Formation of nitrogen-containing metabolites from geniposide and gardenoside by human intestinal bacteria. Planta Med. 1991;57:536-42.

53. Akao T, Kobayashi K, Aburada M. Enzymic studies on the animal and intestinal bacterial metabolism of geniposide. Biol Pharm Bull. 1994;17:1573-6.

54. Sartor B. Microbial influences in inflammatory bowel diseases. Gastroenterology. 2008;134:577-94

55. Aburada M, Takeda S, Sakurai M, Harada M. Pharmacological studies of gardenia fruit. V. Mechanisms of inhibitory effect of genipin on gastric acid secretion and its facilitatory effect on bile secretion in rats. J Pharmacobiodyn. 1980;3:423-33.

56. Miyagoshi M, Amagaya S, Ogihara Y. Structural transformation of geniposide, gardenoside, and related compounds in rat gastrointestinal contents. Planta Med. 1988;54:556-7.

57. Wu X, Zhou Y, Yin F, et al. Quality control and producing areas differentiation of Gardeniae Fructus for eight bioactive constituents by HPLC-DAD-ESI/MS. Biomed Chromatogr. 2014;28:475-85.

58. Yamano T, Tsujimoto $Y$, Noda T, et al. Hepatotoxicity of gardenia yellow color in rats. Toxicol Lett. 1988:44:177-82.

59. Ding Y, Zhang T, Tao JS, et al. Potential hepatotoxicity of geniposide, the major iridoid glycoside in dried ripe fruits of Gardenia jasminoides (Zhi-zi). Nat Prod Res. 2013;27:929-33.

60. Touyama $R$, Takeda $Y$, Inoue $K$, et al. Studies on the blue pigments produced from genipin and methylamine. I. Structures of the brownish-red pigments, intermediates leading to the blue pigments. Chem Pharm Bull. 1994:42:668-73.

\section{Submit your next manuscript to BioMed Central and we will help you at every step:}

- We accept pre-submission inquiries

- Our selector tool helps you to find the most relevant journal

- We provide round the clock customer support

- Convenient online submission

- Thorough peer review

- Inclusion in PubMed and all major indexing services

- Maximum visibility for your research

Submit your manuscript at www.biomedcentral.com/submit 